\title{
Investigating the selectivity of weed harrowing with new methods
}

\author{
J RASMUSSEN*, BM BIBBY ${ }^{\dagger} \& \mathrm{AP}^{*} \mathrm{SCHOU}^{\dagger \dagger}$
}

*Department of Agricultural Sciences, University of Copenhagen, Denmark, ${ }^{\dagger}$ Department of

Biostatistics, University of Aarhus, Denmark, ${ }^{\dagger \dagger}$ Eco-Advice, Jyderup, Denmark.

\section{Summary}

In six field experiments it was investigated whether row spacing, timing, direction and orientation of post-emergence weed harrowing in spring barley influenced the selectivity and whether it is important that increasing intensities of harrowing are generated either by increasing number of passes or increasing driving speed. Selectivity was defined as the relationship between crop burial in soil immediately after treatment and weed control. To estimate crop burial, digital image analysis was used in order to make the estimations objective. The study showed that narrow row spacing decreased selectivity in a late growth stage (21) whereas row spacing in the range of $5.3 \mathrm{~cm}$ to 24 $\mathrm{cm}$ had no effects in an early growth stage (12). Harrowing across rows decreased selectivity in one out of two experiments. Whether repeated passes with the harrowing were carried out in the same orientation along the rows or in alternative orientations forth and back was unimportant. There were indications that high driving speed decreases selectivity and that repeated passes with low driving speed are better than single treatments with high driving speed. Impacts on selectivity, however, were small and only significant at high degrees of weed control. Timing had no significant impact on selectivity.

Correspondence: J Rasmussen, Department of Agricultural Sciences, Faculty of Life Sciences, Copenhagen University, Højbakkegaard Allé 9, DK-2630 Taastrup, Denmark. Tel: (+45) 353334 56; Fax (+45) 353333 84; E-mail: jer[a]life.ku.dk 


\section{Introduction}

Mechanical weed control with an implement such as a weed harrow may control weeds, but also damage crops. Therefore, selectivity defined as the ratio between weed control and crop damage is a key parameter in post-emergence weed harrowing. Low selectivity generally limits weed control because crop damage increases in proportion to weed control. This applies not only to broadcast tillage in cereals and pulses with harrows and rotary hoes (Rasmussen, 1992; Kurstjens \& Perdok, 2000; Lotjonen \& Mikkola, 2000; Jensen et al., 2004) but also to intra-row tillage in row crops with intra-row weeders (Fogelberg \& Gustavsson, 1999; Melander et al., 2005).

Due to low selectivity, post-emergence weed harrowing may reduce crop yields, especially if weed competition is low (Rasmussen, 2004), timing is unfavourable (Rasmussen \& Nørremark, 2006) or implement setting is inappropriate (Böhrnsen, 1993).

Studies show that the primary action with post-emergence harrowing is burying plants (Kurstjens \& Perdok, 2000) even if uprooting has been acknowledged to play an important role in relation to weakly anchored plants (Kurstjens \& Kropff, 2001). In strongly anchored crops such as cereals and grain legumes, burying is the all-important crop damage (Jensen et al., 2004), which justifies the original definition of selectivity as the ratio between weed control and crop damage in terms of crop burial (Rasmussen, 1990; 1992). The percentage of crop burial makes up the so-called crop soil cover, which until recently has been visually assessed immediately after treatment on a scale from $0-100$ percent.

Digital image analysis, however, now offers the possibility to estimate leaf cover and leaf cover changes as a result of harrowing (Hansen et al., 2007; Rasmussen et al., 2007). Hansen et al. (2007) found that the leaf cover changes as a result of harrowing in barley (Hordeum vulgare L.) were unaffected by the presence of weeds, and Rasmussen et al., (2007) made no attempt to discriminate crop and weeds because they considered it unimportant. Weeds were deemed to make up less than a few percentage of the total leaf cover in the early growth stages of spring barley.

Therefore, it is reasonable to calculate crop soil cover from changes in leaf cover as a result of harrowing, based on the preconditions that weeds contribute insignificantly to leaf cover, and uprooting and pulling of crop leaves are insignificant. 
Absolute and objective estimates of crop soil cover calculated from leaf cover resolves two important problems associated with visual assessments of crop soil cover. First, different individuals assess crop soil cover differently and second, statistical analysis based on relative quantities like crop soil cover and weed control, which are calculated relative to untreated plots are problematic due to the interdependence on the reference plots. Furthermore, relative quantities fix the reference value to 1 although the absolute measurement associated with the reference plots are subject to experimental error comparable to that in the other plots.

After the introduction of digital image analysis in weed harrowing research, selectivity may now be estimated on the basis of objective and absolute quantities, leaf cover and weed density. Leaf cover is estimated on the basis of digital image analysis and weed density on the basis of weed counting in the field. It is, however, not trivial to make statistical analysis of the selectivity based on leaf cover and weed density data.

Rasmussen \& Nørremark (2007) proposed a procedure but gave no details about the statistical analysis. The proposed procedure implies two regression analyses and calculation of confidence intervals using the delta-method, which at first sight appear unnecessarily complicated compared to the simpler procedure used in earlier studies (Rasmussen, 1990; 1992; Jensen et al., 2004). The proposed procedure, however, holds several advantages in terms of flexibility, precision, and interpretability as outlined in this paper.

The main purpose of this study is to answer whether row spacing, timing, direction and orientation of harrowing influence the selectivity of weed harrowing and to investigate if it is important whether different intensities are generated by varying the number of passes or the driving speed. Special attention is given to ensuring that this is done in a reliable way that takes the often complex nature of the experimental design into account in the statistical analysis, when analysis is based on leaf cover and weed density data.

\section{Materials and methods}

In order to investigate whether the operational factors (e.g., timing) influence the selectivity, experiments were carried out with progressive series of harrowing intensities (aggressiveness) for each factor or factor combination. Increasing intensity was either created by increasing the number 
of consecutive passes on the same day (Expt 1-6) or by increasing the forward speed (Expt 5-6). In each experiment, tine angle and working depth was adjusted to the soil conditions to make it possible to create a range of crop soil cover from 0 to about $50 \%$ by increasing intensities. Equidistant spacing between the intensity levels was aimed for. Decisions about implement settings were based on visual assessments of crop soil cover in the field in order to achieve the target range of crop soil cover.

\section{Experiments}

Four field experiments were carried out to investigate whether row spacing, timing, direction and orientation of harrowing affect the selectivity of weed harrowing in spring barley, and two experiments were carried out to investigate if it is important to selectivity whether ranges of intensities are generated by varying the number of passes or the driving speed. All experiments were carried outin spring 2006.

Experiments were carried out on an organic farm and a neighbouring conventional farm (Table 1). Both farms are experimental farms owned by the Faculty of Life Science, Copenhagen University and situated about $20 \mathrm{~km}$ west of Copenhagen $\left(55^{\circ} 40^{\prime} \mathrm{N}, 12^{\circ} 18^{\prime} \mathrm{E}\right)$. The soil is a sandy clay loam typical of Zealand. Plots were $3 \times 14 \mathrm{~m}$.

All experiments were carried out in spring barley without herbicide application. One crop density ( 350 seeds $\mathrm{m}^{-2}$ ) and two varieties (Modena on the organic farm and Scandium on the conventional farm) were used. Row spacing was $12 \mathrm{~cm}$ in Expt 2 to 6 but varied in Expt 1 (Table 1). Harrowing was carried out with a 3 m wide flex tine harrow, Økostriglen (A T Hedebo, DK-7970 Redsted M, Denmark). Driving speed was constant within each of the first four experiments but varied between experiments in the range of 4 and $7 \mathrm{~km} \mathrm{~h}^{-1}$. In Expt 5 and 6 the driving speed was varied as an alternative way to create a range of harrowing intensities.

Expt 1. To investigate the importance of row spacing and timing of harrowing, a three factorial split-plot design with four replicate blocks was used. Row spacing $(5.3,12,24 \mathrm{~cm})$ was applied to main plots due to practical considerations related to sowing, and timing and intensity of harrowing as sub-plot treatments. The experiment consisted of 96 plots ( 3 row spacing x 2 timings $\mathrm{x} 4$ intensities of harrowing $\mathrm{x} 4$ replicate blocks). A standard seed drill was used to sow barley at 12 and 
$24 \mathrm{~cm}$ row spacing. A modified precision seed drill (Kverneland Accord Corporation, Soest, Germany) was used to sow barley at $5.3 \mathrm{~cm}$ row spacing in a uniform grid pattern with distance between rows similar to the distance between plants in the same row. The crop was harrowed in growth stage (GS) 12 (Lancashire et al., 1991) and two weeks later in GS 21. The intensity of harrowing was varied by the number of consecutive passes in the range of 0 to 3 . All passes were in the same orientation along crop rows. Implement settings and driving speed were adjusted to timing.

Expt 2. To investigate the importance of direction of harrowing, a two factorial split-plot design with four replicate blocks was used. Direction (along and across rows) was applied to main plots due to practical considerations about harrowing, and intensity of harrowing as sub-plot treatments. The experiment consisted of 32 plots ( 2 directions $x 4$ intensities x 4 replicate blocks). The intensity of harrowing was varied by the number of consecutive passes in the range of 0 to 3 . All passes were in the same direction along or across the crop rows.

Expt 3. As Expt 2 but direction was substituted with orientation, either all passes along the rows in the same orientation or passes in alternating orientations, back and forth along the rows. The number of passes was $0,2,3$ and 4 .

Expt 4. As Expt 2 but in an earlier growth stage and with other weed species (another field).

Expt5. To investigate whether it is important in which way the range of intensities is generated, by varying the number of passes or by varying the driving speed, a two factorial split-plot design with four replicate blocks was used. Passes and speed (mode of intensity) were applied to main plots and intensity as sub-plot treatments. Five intensity levels were used. The range of intensities was either created by (0), 1, 2, 3 and 4 consecutive passes with $3 \mathrm{~km} \mathrm{~h}^{-1}$ or by one harrowing pass with (0), 3 , 6,9 and $12 \mathrm{~km} \mathrm{~h}^{-1}$. In the statistical analyses, intensities were transformed into a common intensity scale ranging from 0 to 4 independently of mode as shown in Fig. 4. The experiment consisted of 40 plots ( 2 modes of intensity x 5 levels of intensity x 4 replicate blocks). All harrowing passes were in the same orientation along crop rows. 
Table 1. Experimental factors, dominating weed species and crop growth stages (GS) and leaf cover index at the time of harrowing. All experiments included 4 or 5 graded levels of harrowing intensity to create progressive series of harrowing.

\begin{tabular}{|c|c|c|c|c|}
\hline Experiment & $\begin{array}{l}\text { Experimental } \\
\text { factors }\end{array}$ & $\begin{array}{l}\text { Crop growth stage } \\
\text { (GS) and percent leaf } \\
\text { cover in untreated } \\
\text { plots at treatment in } \\
\text { brackets }\end{array}$ & Dominating weed species & $\begin{array}{l}\text { Growing } \\
\text { system }\end{array}$ \\
\hline 1 & $\begin{array}{l}\text { Row spacing } \\
-5.3 \mathrm{~cm} \\
-12 \mathrm{~cm} \\
-24 \mathrm{~cm} \\
\text { GS } \\
-12 \\
-21\end{array}$ & $\begin{array}{l}\text { GS } 12 \\
(21 \%, 14 \%, 15 \% \text { for } \\
\text { increasing row } \\
\text { spacing) } \\
\text { GS } 21 \\
(70 \%, 51 \%, 46 \% \text { for } \\
\text { increasing row } \\
\text { spacing) }\end{array}$ & $\begin{array}{l}\text { Capsella bursa-pastoris } \\
\text { (L.) MEDIK, } \\
\text { Chenopodium album L., } \\
\text { Polygonum persicaria } \\
\text { L.,Viola arvensis MURR all } \\
\text { at the cotyledon to 2-leaf } \\
\text { stage }\end{array}$ & Organic \\
\hline 2 & $\begin{array}{l}\text { Direction } \\
\text { - along rows } \\
\text { - across rows }\end{array}$ & $\begin{array}{l}\text { GS } 13 \\
(30 \%)\end{array}$ & $\begin{array}{l}\text { Polygonum persicaria L. } \\
\text { Chenopodium album L. } \\
\text { Viola arvensis MURR. all at } \\
\text { the cotyledon to } 2 \text {-leaf stage }\end{array}$ & Conventional \\
\hline 3 & $\begin{array}{l}\text { Orientation } \\
\text { - all passes in } \\
\text { one orientation } \\
\text { along rows } \\
\text { - alternating } \\
\text { orientation of } \\
\text { passes, back } \\
\text { and forth }\end{array}$ & $\begin{array}{l}\text { GS } 13 \\
(33 \%)\end{array}$ & As above - same field & Conventional \\
\hline 4 & $\begin{array}{l}\text { Direction } \\
\text { - Along rows } \\
\text { - Across rows }\end{array}$ & $\begin{array}{l}\text { GS } 12 \\
(18 \%)\end{array}$ & $\begin{array}{l}\text { Chenopodium album, } \\
\text { Polygonum convolvulus L. } \\
\text { Stellaria media L.,Capsella } \\
\text { bursa-pastoris (L.) MEDIK } \\
\text { all at the cotyledon to 2-leaf } \\
\text { stage. }\end{array}$ & Conventional \\
\hline 5 & $\begin{array}{l}\text { Mode of } \\
\text { intensity } \\
\text { - Passes } \\
\text { - Driving speed }\end{array}$ & $\begin{array}{l}\text { GS } 12 \\
(12 \%)\end{array}$ & $\begin{array}{l}\text { Chenopodium album, } \\
\text { Polygonum convolvulus L., } \\
\text { Polygonum aviculare L., } \\
\text { Sinapis arvensis L. all at the } \\
\text { cotyledon stage, }\end{array}$ & Organic \\
\hline 6 & $\begin{array}{l}\text { Mode of } \\
\text { intensity } \\
\text { - Passes } \\
\text { - Driving speed }\end{array}$ & $\begin{array}{l}\text { GS } 12 \\
(9 \%)\end{array}$ & As above - same field & Organic \\
\hline
\end{tabular}


Expt 6. As Expt 5, except that only 4 levels of intensities were used at lower driving speeds; $0,1,2$, and 3 consecutive passes with $2 \mathrm{~km} \mathrm{~h}^{-1}$ and one pass with $0,2,4,6 \mathrm{~km} \mathrm{~h}^{-1}$. The experiment consisted of 32 plots ( 2 modes of intensity x 4 levels of intensities x 4 replicate blocks).

\section{Crop and weed assessments}

Digital images were captured with two compact digital cameras, Canon Digital IXUS 55 Silver (Canon INC, USA) (2592 X 1944 pixels) and Olympus C750UZ (Olympus Optical Co., Ltd.) (2288 $\mathrm{X} 1712$ pixels) and within each experiment only one camera was used. Automatic white balancing, shutter speed and aperture value were used and images were checked before digital image analysis to secure correct focus and exposure. Four pictures each covering about $1 \mathrm{~m}^{2}$ (vertical projection) were captured in each plot immediately after harrowing. Natural light conditions were used. Stable light conditions were aimed at within each experiment but if light conditions were fluctuating due to shifting cloud cover, at least one block replicate was photographed in stable light conditions. Digital images were analysed with the automated procedure described in Rasmussen et al. (2007), which is programmed in MATLAB (MathWorks, Inc, MA, USA) and later converted into a free web-based software (www.imaging-crop.dk). The outcome of the analysis is a leaf cover index, which is the proportion of pixels in the images determined to be green. There is no distinction between crop and weeds and re-growth was not considered. It was evaluated that weeds contributed insignificantly to the leaf cover index, and that uprooting and pulling of leaves of the crop plants was unimporatnt.

Weed density was assessed the same day as plots were harrowed. Within each plot, weed densities in 4 random circles of $0.25 \mathrm{~m}^{-2}$ were counted. Re-growth of weeds and crop was not considered.

\section{Models and statistics}

We propose to use the two-step procedure outlined in Rasmussen \& Nørremark (2007), which we consider to be the best procedure from a statistical perspective because it (1) allows analysis of the absolute crop and weed quantities, (2) uses the predetermined intensity as a covariate and not the leaf cover index (which is subject to measurement error), and (3) allows the experimental design (split-plot) to be reflected in the statistical analysis. The original analysis procedure proposed by Rasmussen (1990) and later used by others (Melander, 1997; Jensen et al., 2004) does not have any of these advantages. 
In the first step, leaf cover index $(L)$ and weed density $(W)$ are analysed as funcbtions of the intensity of weed harrowing $(I)$ and in the second step, the relationship between weed control (= percentage reduction of weed density in relation to untreated) and crop soil cover (=percentage reduction of leaf cover index in relation to untreated) is estimated on the basis of parameter estimates from the first step.

In all experiments leaf cover index $(L)$ was described by a negative exponential equation

$L=L_{0} \cdot \exp (-b \cdot I)$

where $L_{0}$ is the leaf cover index in untreated reference plots, $I$ is the intensity of harrowing and $b$ is the slope parameter. In general, $I$ was the number of passes but in Expt 5 and $6, I$ also expressed increasing driving speeds. The lowest driving speed in Expt 5 and 6, respectively, which was identical to the driving speed used to create the series of intensities by increasing number of passes, was given the value of 1 .

Weed density $(W)$ is described as a function of the intensity of harrowing. Depending on the actual relationship between weed density and intensity, the following functions were used:

$$
\begin{aligned}
& W=W_{0} \cdot \exp (-C \cdot I) \\
& W=W_{0} \cdot \exp (-C \cdot \ln (I+1)) \\
& W=W_{0} \cdot \exp \left(-C \cdot I^{0.25}\right)
\end{aligned}
$$

where $W_{0}$ is the weed density in untreated plots, $I$ is the intensity of harrowing and $c$ is the slope parameter. Eqn (2) to (4) express a progression in terms of curvature. In Eqn (2), the first harrowing pass reduces weed density by the same percentage as each of the following passes. In Eqn (3) the first pass is more efficient than the following passes and in Eqn (4) this trait is further intensified.

Simple regression models were compared to analysis of variance models to test for lack-of-fit. This was done separately for the factors under investigation in each experiment based on Eqn (1) to (4) on a logarithmic scale. The parameters $L_{0}, b, W_{0}$, and $c$ were estimated using mixed linear models with intensity of harrowing as a covariate and the investigated factors (and interactions) as fixed 
effects, and block and the interaction between whole plot factors and block (whole plots) as random effects. In order to omit non-significant factor or factor combination effects on parameters, successive approximate F-tests were made to reduce the complexity of models. In all cases, it was decided to analyse the logarithm of leaf cover index and weed density after inspecting the residuals.

In the second step, weed control was estimated relative to crop soil cover to reveal the selectivity and to calculate the degree of crop soil cover that was associated with $80 \%$ weed control. Approximate $95 \%$-confidence $(95 \%$-CI) intervals were determined using the delta-method (the method of approximating a non-linear expression in $b$ and $c$ by a linear) and a correlation between estimates of $b$ and $c$ of 0.8 (based on what was found in the analysis of a single row spacing in Expt $1)$.

When Eqn (2) describes weed density, the relationship between weed control ( $\left.\mathrm{WC}=100\left(1-W / W_{0}\right)\right)$ and crop soil cover $\left(\mathrm{CSC}=100\left(1-L / L_{0}\right)\right)$ is deduced from Eqn (1) and (2)

$W C=100 \cdot\left(1-\exp \left(\frac{c}{b} \cdot \ln \left(1-\frac{C S C}{100}\right)\right)\right)$

When Eqn (3) describes weed density, rearranging Eqn (1) and (3) gives

$W C=100 \cdot\left(1-\left(1-\frac{1}{b} \ln \left(1-\frac{C S C}{100}\right)\right)^{-c}\right)$

When Eqn (4) describes weed density, rearranging Eqn (1) and (4) gives

$$
W C=100 \cdot\left(1-\exp \left(-C \cdot\left[-\frac{1}{b} \ln \left(1-\frac{C S C}{100}\right)\right]^{0.25}\right)\right)
$$

At a first glance it might seem more natural to use expressions (2a) to (4a) directly in order to estimate $L_{0}, b, W_{0}$, and $c$ using non-linear regression. It is not obvious, however, how to include fixed and random effects in a non-linear regression analysis and in all events it will lead to having to rely on large-sample approximate tests. It also seems questionable to ignore the error associated 
with the measurement of leaf cover index (and thereby the error in crop soil cover) which would be implied by such an analysis.

Selectivity, calculated as the ratio between WC and CSC may easily be plotted against WC from the above equations like in the early papers about selectivity (Rasmussen 1990;1992) but we decided to evaluate the selectivity from plots where WC is plotted against CSC as in more recent papers on selectivity (Melander, 1997; Jensen et al., 2004; Melander et al. 2005)

All statistical analyses were performed with PROC MIXED in SAS (SAS version 9.1, SAS Institute, Cary, USA).

\section{Results}

Lack-of-fit tests showed that Eqn (1) described the decline of the leaf cover index with increasing intensity of harrowing well in all experiments $(P>0.05)$, which means that the leaf cover index decreases exponentially with increasing intensity of harrowing. Parameter estimates of $b$, which expresses the decline rate, varied within the range of 0.097 to 0.391 (Table 2), which corresponds to $9 \%$ to $32 \%$ relative decline in leaf cover index per unit of intensity.

As opposed to the leaf cover index, the weed density decreases with increasing intensity of harrowing was not properly described by a simple exponential function in all experiments. Lack-offit tests showed that Eqn (2) only gave appropriate description of the data in Expt 4. In Expt 1, 2 and 3, Eqn (3) provided better descriptions of the weed density responses and passed the lack-of-fit test, and in Expt 5 and 6, Eqn (4) gave good descriptions.

\section{Experiment 1}

The rate of decline of the leaf cover index with increasing harrowing intensity (Parameter $b$ ) was influenced by the row spacing in the late growth stage $(P<0.05)(\mathrm{GS} 21)$, whereas there was no impact of row spacing in the early growth stage $(P=0.23)$ (GS 12) (Fig. 1). Based on the parameter estimates in Table 2, it was calculated from Eqn (1) that each pass reduced leaf cover index by $9 \%$ (95\%-CI: $1 \%$-17\%) at $24 \mathrm{~cm}$ row spacing, by $16 \%$ (95\%-CI: $8 \%-24 \%$ ) at $12 \mathrm{~cm}$ and by $25 \%(95 \%$ CI: $19 \%-31 \%$ ) at $5.3 \mathrm{~cm}$ in the late GS 21 . In the early GS 12 , leaf cover index was reduced by $24 \%$ (95\%-CI: 16\%-32\%) independently of row spacing. 
Weed density was well described by Eqn (3), which means that the relative efficacy of weed harrowing declined by increasing intensities. Weed density decline was unaffected by row spacing $(P=0.53)$ but the decline has higher at the earliest timing $(\mathrm{P}<0.0001)$ (Table 2$)$.

In the early growth stage (GS 12), the selectivity was unaffected by row distance (Fig. 1) due to identical $b$ and $c$ parameters (Table 2). The selectivity, however, was improved by increasing row spacing in GS 21 and 80\% weed control was associated with almost three time higher crop soil cover at $5.3 \mathrm{~cm}$ row spacing compared with $24 \mathrm{~cm}$ in GS 21 (Table 2).

In the early growth stage (GS 12) 80\% weed control resulted in 17\% (95\%-CI: 15\%-19\%) crop soil cover at all row spacings, showing that the selectivity declined over time for the $5.3 \mathrm{~cm}$ row spacing whereas the was no statistical evidence of changes in selectivity for $12 \mathrm{~cm}$ and $24 \mathrm{~cm}$ row spacing (Table 2). 
Table 2. Parameter estimates with estimated standard errors and estimated crop soil cover corresponding to $80 \%$ weed control. Parameters $b$ and $c$ express the rate of decline of leaf cover index and weed density with increasing intensity of weed harrowing.

\begin{tabular}{|c|c|c|c|c|}
\hline Experiment & Factor & $\begin{array}{l}\text { Decline of leaf cover } \\
\text { index - Parameter } b \\
\text { in Eqn (1) (standard } \\
\text { error) }\end{array}$ & $\begin{array}{l}\text { Decline of weed } \\
\text { density - Parameter } \\
c \text { (standard error) }\end{array}$ & $\begin{array}{l}\text { Estimated crop soil } \\
\text { cover }(\%) \\
\text { corresponding to } 80 \% \\
\text { weed control }(95 \% \text { - } \\
\text { CI) }\end{array}$ \\
\hline 1 & $\begin{array}{l}\text { GS } 12 \\
-5.3 \mathrm{~cm} \\
-12 \mathrm{~cm} \\
-24 \mathrm{~cm} \\
\mathrm{GS} 21 \\
-5.3 \mathrm{~cm} \\
-12 \mathrm{~cm} \\
-24 \mathrm{~cm} \\
\end{array}$ & $\begin{array}{l}0.278(0.0308) \\
0.278(0.0308) \\
0.278(0.0308) \\
0.282(0.0533) \\
0.175(0.0533) \\
0.097(0.0533)\end{array}$ & $\begin{array}{l}3.13(0.144)^{\ddagger} \\
3.13(0.144)^{\ddagger} \\
3.13(0.144)^{\ddagger} \\
1.88(0.144)^{\ddagger} \\
1.88(0.144)^{\ddagger} \\
1.88(0.144)^{\ddagger}\end{array}$ & $\begin{array}{l}17 \%(15 \%-19 \%) \\
17 \%(15 \%-19 \%) \\
17 \%(15 \%-19 \%) \\
32 \%(26 \%-38 \%) \\
21 \%(13 \%-29 \%) \\
12 \%(2 \%-22 \%)\end{array}$ \\
\hline 2 & $\begin{array}{l}\text { Direction } \\
\text { - along rows } \\
\text { - across rows }\end{array}$ & $\begin{array}{l}0.187(0.0193) \\
0.187(0.0193)\end{array}$ & $\begin{array}{l}1.47(0.134)^{\ddagger} \\
1.47(0.134)^{\ddagger}\end{array}$ & $\begin{array}{l}31 \%(27 \%-35 \%) \\
31 \%(27 \%-35 \%)\end{array}$ \\
\hline 3 & $\begin{array}{l}\text { Orientation } \\
\text { - all passes in one } \\
\text { orientation along } \\
\text { rows } \\
\text { - alternating } \\
\text { orientation of } \\
\text { passes, back and } \\
\text { forth } \\
\end{array}$ & $\begin{array}{l}0.176(0.0152) \\
0.176(0.0152)\end{array}$ & $\begin{array}{l}1.81(0.228)^{\ddagger} \\
1.81(0.228)^{\ddagger}\end{array}$ & $\begin{array}{l}22 \%(17 \%-27 \%) \\
22 \%(17 \%-27 \%)\end{array}$ \\
\hline 4 & $\begin{array}{l}\text { Direction } \\
\text { - Along rows } \\
\text { - Across rows } \\
\end{array}$ & $\begin{array}{l}0.241(0.0451) \\
0.391(0.0451)\end{array}$ & $\begin{array}{l}1.13(0.120)^{\dagger} \\
1.13(0.120)^{\dagger}\end{array}$ & $\begin{array}{l}29 \%(23 \%-35 \%) \\
43 \%(38 \%-47 \%)\end{array}$ \\
\hline 5 & $\begin{array}{l}\text { Mode of intensity } \\
\text { - Passes } \\
\text { - Driving speed } \\
\end{array}$ & $\begin{array}{l}0.312(0.0198) \\
0.229(0.0198)\end{array}$ & $\begin{array}{l}3.26(0.246)^{\S} \\
2.23(0.246)^{\S} \\
\end{array}$ & $\begin{array}{l}2 \%(1 \%-3 \%) \\
6 \%(2 \%-10 \%)\end{array}$ \\
\hline 6 & $\begin{array}{l}\text { Mode of intensity } \\
\text { - Passes } \\
\text { - Driving speed }\end{array}$ & $\begin{array}{l}0.113(0.0177) \\
0.113(0.0177)\end{array}$ & $\begin{array}{l}2.59(0.216)^{\S} \\
1.88(0.216)^{\S}\end{array}$ & $\begin{array}{l}2 \%(1 \%-3 \%) \\
7 \%(2 \%-11 \%)\end{array}$ \\
\hline
\end{tabular}

$\dagger$ in Eqn 2

$\$$ in Eqn 3

$\S$ in Eqn 4 

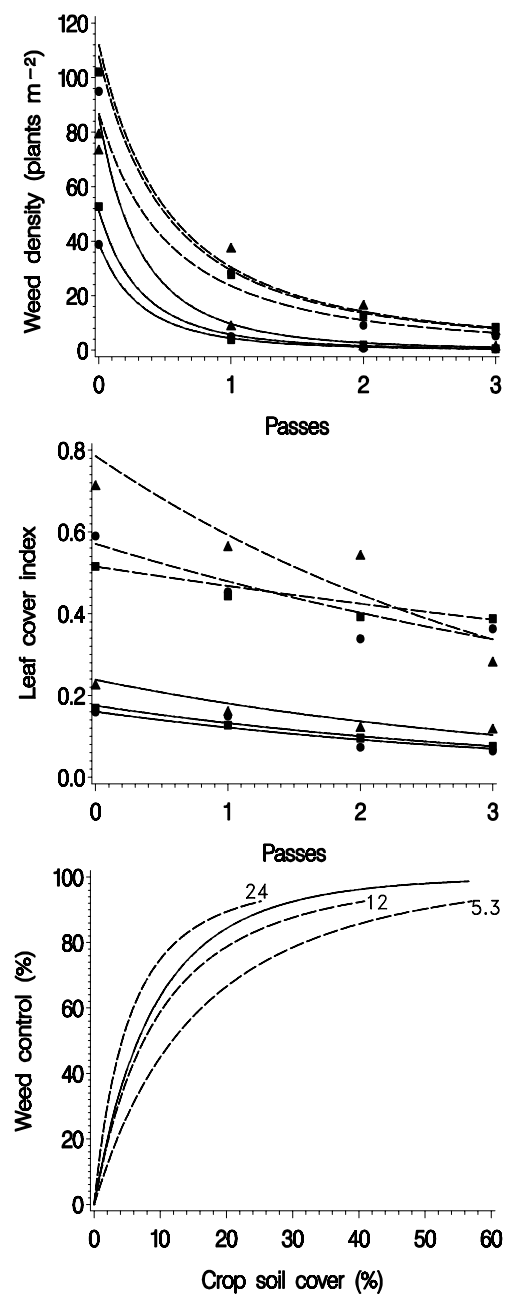

Fig. 1. Weed density and leaf cover index index as functions of harrowing passes (intensity) for different row spacing and timing in Expt 1 and predicted selectivity curves (weed control versus crop soil cover). Curves are predicted from Eqn (1), (3) and (3a) and parameters are given in Table 2. Numbers associated with the dashed curves denote row spacing. Solid curves correspond to GS 12 and dashed curves correspond to harrowing in GS 21. Symbols: $\boldsymbol{\Delta}=5.3 \mathrm{~cm}$ row distance, $\bullet=$ $12 \mathrm{~cm}$ row distance, $\mathbf{\square}=24 \mathrm{~cm}$ row distance. 


\section{Experiment 2 and 3}

Increasing intensities of harrowing along and across the rows resulted in the same decline of leaf cover index $(P=0.12)$ and weed density $(P=0.47)$ (Table 2$)$, and it was unimportant whether harrowing passes were repeated in the same orientation along the crop rows or in alternating orientations (back and forth) with respect to leaf cover index $(P=0.54)$ and weed density $(P=$
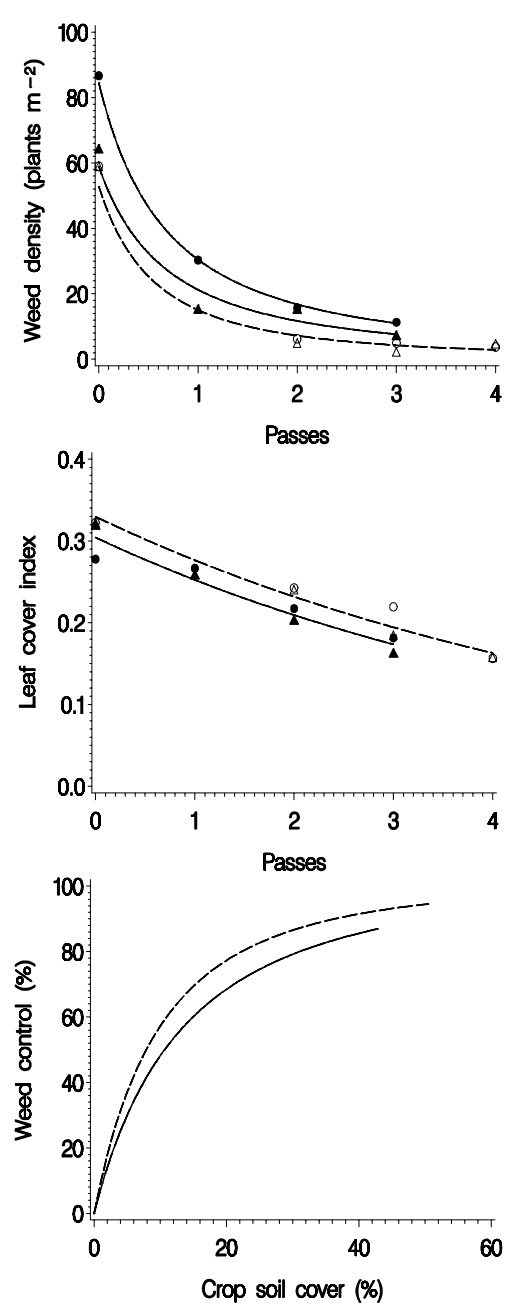

Fig. 2. Weed density and leaf cover index as functions of harrowing passes (intensity) for different directions (Expt 2) and orientations of harrowing (Expt 3) and predicted selectivity curves. Curves are predicted from Eqn (1), (3) and (3a) and parameters are given in Table 2. Solid curves correspond to Expt 2 and dashed curves to Expt 3. Symbols: $\boldsymbol{\Delta}=$ harrowing along the rows, $\bullet=$ harrowing across the rows, $\bigcirc=$ all passes in the same orientation along the rows, $\Delta=$ passes in alternating orientation back and forth along the rows. 
0.64). In consequence, the predicted selectivity curves were unaffected by harrowing direction and orientation (Fig. 2). The selectivity was higher in Expt 3 even if crop and weeds were in the same growth stages.

\section{Experiment 4}

The rate of decline of the leaf cover index was higher when harrowing was carried out across the rows $(P=0.006)$, whereas the impacts on weed density was unaffected by the direction of harrowing $(P=0.51)$ (Table 2$)$ giving lower selectivity across the rows (Fig. 6).

\section{Experiment 5 and 6}

Increasing the number of passes gave higher impacts on leaf cover index $(P=0.002)$ and weed density $(P=0.001)$ than increasing the driving speed (Table 2$)$. The very high percentage of weed control achieved by the lowest intensity required Eqn (4) to give a good description of the weed densities (Fig. 4). The experiment was repeated because the intensities were considered to be too aggressive in terms of weed impacts. In Expt 6, however, the impacts on weeds were still high but the crop impacts were lower due to lower driving speeds (Table 2).

In Expt 6, the impacts on weed densities were higher when the number of passes was increased ( $P$ $<0.0001)$ compared to driving speed but there were no differences in the decline of leaf cover index $(P=0.74)$.

Both experiments showed a tendency of higher selectivity when the intensity was increased through increasing number of passes with a low driving speed but at $80 \%$ weed control there was no statistical evidence of a difference due to overlapping confidence intervals in terms of crop soil cover (Table 2). 

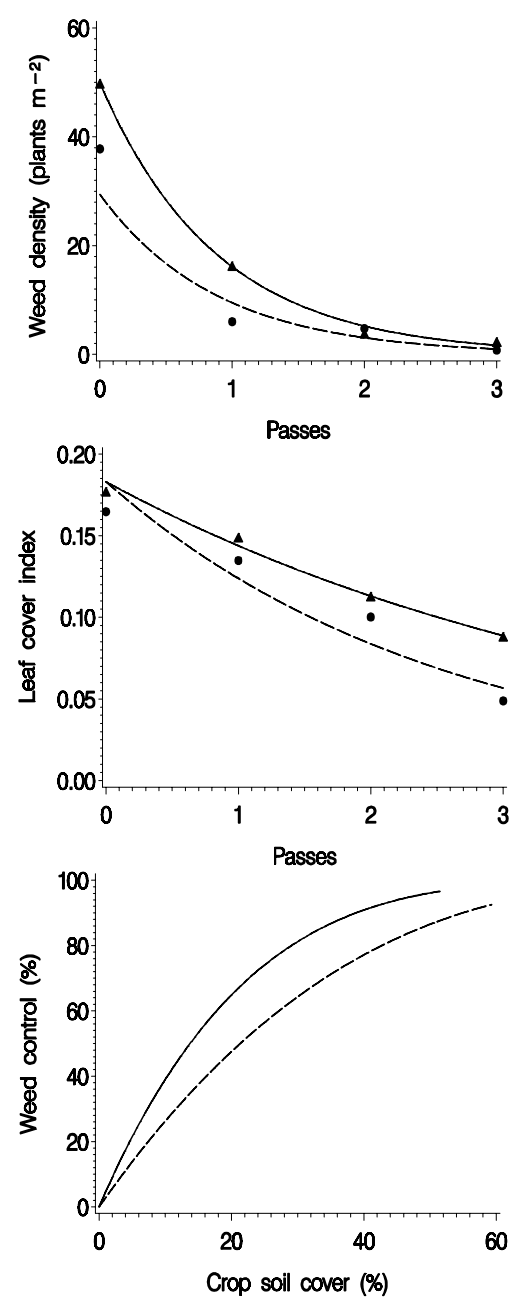

Fig. 3. Weed density and leaf cover index as functions of the number of passes (intensity) for different directions of harrowing in Expt 4 and predicted selectivity curves. Curves are predicted from Eqn (1), (2) and (2a) and parameters are given in Table 2. Solid curves correspond to harrowing along the rows and dashed curves to harrowing across the rows. Symbols: $\Delta=$ harrowing along the rows, $\bullet=$ harrowing across the rows. 

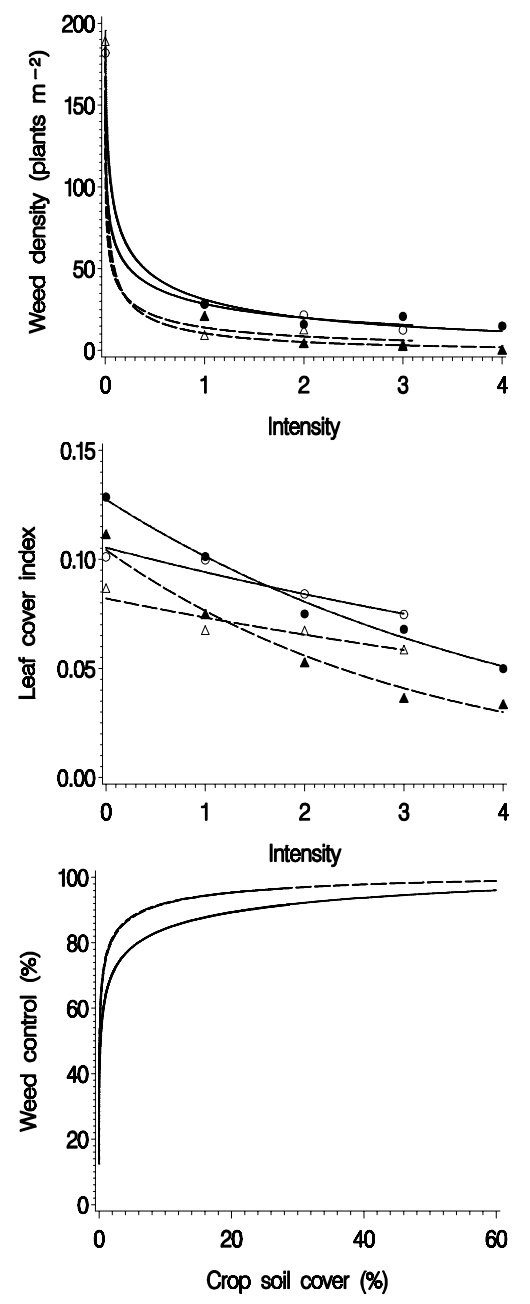

Fig. 4. Weed density and leaf cover index as functions of the intensity expressed either as passes or driving speed in Expt 5 and 6 and predicted selectivity curves. Curves are predicted from Eqn (1), (4) and (4a) and parameters are given in Table 2. Dashed curves correspond to passes and solid curves to speed. Symbols: $\boldsymbol{\Delta}=$ intensity expressed in terms of passes, $\bullet=$ intensity expressed in terms of driving speed. Expt 5 (closed symbols) has intensity levels in the range of 0 to 4 and Expt 6 (open symbols) in the range of 0 to 3.

\section{Discussion}

On the assumption that weeds, uprooted plants and pulled leafs contribute insignificantly to the leaf cover index, our study shows that a procedure for objective analysis of selectivity in physical weed 
control is now available. The proposed procedure has similarities to the dose-response concept used to assess herbicidal selectivity (Streibig, 1988; Ritz et al., 2006) but also important dissimilarities.

Assessment of herbicidal selectivity is based on comparisons of sigmoidal dose-response curves at specific response levels. Our estimation procedure is also based on response curves and comparisons of crop and weed responses. However, we found no evidence of sigmoidal relationships between plant responses and intensity and we eliminated intensity in our models that describe the selectivity (Eqn (2a-4a)).

Since our data could not be described with symmetric sigmoidal and parallel response curves, selectivity could not be expressed relative to the intensity with a single parameter as for some herbicides (Streibig, 1988). This is why we presented selectivity curves (weed control plotted against crop soil cover) and calculated confidence intervals for the crop soil cover corresponding to $80 \%$ weed control. Other weed control levels can be used as well but $80 \%$ was chosen because it is attainable in experiments with graded levels of intensities and because possible differences in selectivity are more pronounced at higher levels of weed control than at lower levels.

We eliminated the intensity from our presentation of the selectivity, because there exists an important difference between the dose concept used in herbicidal research and the intensity concept used in mechanical weed control research. A dose is referring to a certain amount of an herbicide but an intensity only expresses the tillage aggressiveness through driving speed or number of passes without referring to the active ingredient, which is the soil and its dynamic properties. Therefore, an intensity level is a more arbitrary and context dependent measure in terms of plant responses than a herbicide dose due to strong interactions between tillage implement and soil (Duerinckx et al., 2005).

This study showed higher selectivity in spring barley than previous studies (Rasmussen, 1990; 1992, Rasmussen \& Svenningsen, 1995), but comparisons to earlier studies may be unreliable due to visual assessments of the crop soil cover. In this study, crop soil cover associated with $80 \%$ weed control at $12 \mathrm{~cm}$ row spacing and harrowing along crop rows was in the range of 2 to $31 \%$ averaging $15 \%$. 
Expt 5 and 6 indicate that it may be of some importance to selectivity how increasing intensities are created in the field. Increasing the number of passes with a low driving speed was marginally better in terms of selectivity than increasing the driving speed of a single pass, even if the difference was not statistical significant at 80\% weed control (Table 2). Also Rasmussen (1990) found that high driving speeds possibly may have negative impacts on the selectivity, even if the experimental design was inadequate to test whether the intensity preferably should be increased through number of passes instead of driving speed. However, Expt 5 and 6 were problematic, because the applied intensities were too high to give good descriptions of the weed density decline relative to the graded levels of intensities. The lowest level of intensity gave very high percentages of weed control that approached the upper limit of weed control (Fig. 4). Furthermore, there was strong evidence, that the factor under investigation (mode of intensity) was related to the general growth conditions in the field, because the general level of leaf cover index was lower in plots where the intensity was varied by number for passes (Fig 4). This may indicate that the crop and possibly also the weeds were in an earlier growth stage, which challenges the conclusions from Expt 5 and 6. Leaf cover index assessment before treatments used as a covariate to adjust for pre-treatment variation, a complete randomized block design, and less aggressive treatments would all have improved the experiments.

If the lower selectivity associated with higher driving speed in Expt 5 and 6 is general, it challenges the assumption that different intensities of harrowing carried out on the same site and day always will give identical selectivity curves independently of the operational factors according to harrowing (Rasmussen, 1992). Kurstjens and Perdok (2000) challenged this assumption in lab experiments, but it has never been challenged in previous field experiments.

Expt 4 also challenged the assumption because harrowing across the rows resulted in lower selectivity than harrowing along the rows (Fig 3). Rydberg's (1994) results seem to support this result but his results were not statistical significant. Expt 2, however, showed that harrowing across rows do not always influence the selectivity (Fig 2).

Timing was only of minor importance in Expt 1 which is supported by Rydberg (1993), who found minor differences in selectivity in growth stage 12 and 13. Rasmussen (1992) found that the selectivity increased over time whereas Melander (1997) found dramatically negative effects of delayed treatments in seeded onions. Jensen et al. (2004) found no effect of timing in lupin 
(Lupinus luteus L. and Lupinus angustifolius L.), which underlines that the understanding of how timing influences the selectivity is insufficient and results conflicting.

Based on previous experiments, it was expected that widening the row spacing in general would result in higher selectivity (Rasmussen \& Svenningsen, 1995), but this study showed that selectivity only was affected by row spacing in the late GS 21 , indicating that early post-emergence weed harrowing may be used successfully in narrow rowed cropping systems like the spatial uniformity system proposed by Weiner et al. (2001). It is generally accepted that the competitive ability of crops increases when the row spacing are narrowed (Weiner et al., 2001) and crop yield decreases by increasing row spacing (Kirkland, 1993; Neumann et al., 2006). In advanced growth stages, however, there seems to be a trade-off between a lower selectivity and a higher competitive ability of the crops in narrow rowed systems.

In conclusion, this study shows that narrow row spacing and harrowing across rows may decline selectivity but the importance of row spacing was only significant in late growth stages (GS 21) and the direction of harrow was only significant in one out of two experiments. There are indications that high driving speed declines selectivity, but this issue needs further investigations. Whether repeated harrowings are carried out in the same orientation along the rows or in alternative orientations forth and back was unimportant. Timing had no significant impact on selectivity.

\section{Acknowledgement}

We thank Micahel Nørremark for assistance with the digital image analysis programme and two anonymous referees for their contributions to the improvement of the manuscript.

\section{Referencens}

BÖHRNSEN A (1993) Several years results about mechanical weeding in cereals. Communications of the 4th International Conference I.F.O.A.M. Non Chemical Weed Control, Dijon, France, 95101.

DUERINCKX K, MOUAZEN AM, ANTHONIS J \& RAMON H (2005) Effects of spring-tine settings and operational conditions on the mechanical performance of a weed harrow tine Biosystems Engineering 91(1), 21-34. 
FOGELBERG F \& GUSTAVSSON AMD (1999) Mechanical damage to annual weeds and carrots by inrow brush weeding. Weed Research 39, 469-479.

HANSEN PK, RASMUSSEN IA, HOLST N \& ANDREASEN C (2007) Tolerance of four spring barley (Hordeum vulgare) varieties to weed harrowing. Weed Research 47, 241-251.

JENSEN RK, RASMUSSEN J, \& MELANDER B (2004) Selectivity of weed harrowing in lupin. Weed Research, 44, 245-253.

KIRKLAND KJ (1993) Weed management in spring barley (Hordeum vulgare) in the absence of herbicides. Journal of Sustainable Agriculture 3 (3-4), 95-104.

KURSTJENS DAG \& KROPFF M J (2001) The impact of uprooting and soil-covering on the effectiveness of weed harrowing. Weed Research 41, 211-228

KURSTJENS DAG \& PERDOK UD (2000) The selective soil covering mechanism of weed harrows on sandy soil. Soil \& Tillage Research 55, 193-206.

Lancashire PD, Bleiholder H, Van Den Boom T et al. (1991) A uniform decimal code for the growth stages of crops and weeds. Annals of Applied Biology 119, 561-601.

LOTJONEN T \& MiKKOLA H (2000) Three mechanical weed control techniques in spring cereals. Agricultural and Food Science in Finland 9(4) 269-278.

MELANDER B (1997) Optimization of the adjustment of a vertical axis rotary brush weeder for intrarow weed control in row crops. Journal of Agricultural Engineering Research 68 (1), 39-50.

MELANDER B, RASMUSSEN IA \& BARBERI P (2005) Integrating physical and cultural methods of weed control - Examples from European research. Weed Science 53, 369-81.

Neumann H, Loges R \& Taube F (2006) Das System "weite Reihe" - Innovation für den ökologischen Winterweizenanbau? (The wide row system - Innovation for organic winter wheat cultivation?) Berichte über Landwirtschaft 84, 404-424.

RASMUSSEN IA (2004) The effect of sowing date, stale seedbed, row width and mechanical weed control on weeds and yields of organic winter wheat. Weed Research 44, 12-20.

RASMUSSEN J (1990) Selectivity, an important parameter on establishing the optimum harrowing technique for weed control in growing cereals. Proceedings of the 1990 European Weed Research Society Symposium, Integrated weed management in cereals. Helskinki, Finland, 197-204.

RASMUSSEN J (1992) Testing harrows for mechanical control of annual weeds in agricultural crops. Weed Research 32, 267-274. 
RASMUSSEN J \& NøRREMARK M (2006) Digital image analysis offers new possibilities in weed harrowing research. Zemdirbyste/Agriculture. 93(4), 155-165.

RASMUSSEN J \& NøRREMARK M (2007) Digital images for assessing soil cover of crop plants. In: Proceedings 7th EWRS Workshop on Physical and Cultural Weed Control, Salem, Germany, 11-14 March, 123-129.

RASMUSSEN, J. \& SVENNINGSEN T (1995): Selective weed harrowing in cereals. Biological Agriculture and Horticulture 12: 29-46.

RASMUSSEN J, NøRREMARK M \& BIBBY BM (2007) Assessment of leaf cover and crop soil cover in weed harrowing research using digital images. Weed Research 47, 299-310.

Ritz C, CEDERgREen N, JENSEN JE \&T STREIBIG JC (2006) Relative potency in nonsimilar doseresponse curves. Weed Science 54, 407-412.

RYDBERG T (1993) Weed harrowing-driving speed at different stages of development. Swedish Journal of Agricultural Research 23, 107-113.

RYDBERG T (1994) Weed Harrowing - the Influence of Driving Speed and Driving Direction on Degree of Soil Covering and the Growth of Weed and Crop Plants. Biological Agriculture \& Horticulture 10, 197-205.

STREIBIG JC (1988) Herbicide bioassay. Weed Research 28, 479-484.

WEINER J, GRIEPENTROG HW \& KRISTENSEN L (2001): Suppression of weeds by spring wheat Triticum aestivum increases with crop density and spatial uniformity. Journal of Applied Ecology 38, 784-790. 